\title{
RAYAS EXTRAVAGANTES: TRES TRISTES TIGRES \\ Y EL NEOBARROCO CUBANO
}

\author{
POR
}

\author{
WILLIAM L. SIEMENS \\ West Virginia University
}

En la filosofía de la Iglesia Católica durante la Edad Media y El Renacimiento hubo una lucha más o menos constante entre dos teorias en cuanto a la realidad. Por un lado la famosa "cadena del ser", según la cual existía una serie de gradaciones entre lo más exaltado y lo más degradado. En contraste, en un sistema indudablemente más primitivo, se creía que lo material servía como una expresión de lo ideal, siendo aquéllo infinitamente inferior a esto, que es perfecto. Por lo tanto, todo lo material debe aspirar a mejorarse según las normas de lo ideal. En la práctica, esto se expresa en obras como Imitatio Christi de Tomás à Kempis y, más tarde, en el uso por los artistas de la mitología clásica como decorado.

En la arquitectura barroca se trata de una estructura básica, francamente material y utilitaria, con un nivel añadido correspondiente al reino de la gracia, de lo ideal, de la belleza pura. Muchas veces se trata del uso de figuras sacadas de la mitología, donde los personajes tanto como los acontecimientos pertenecen a un espacio y a un tiempo propios. En la época del neoclasicismo se buscaría la forma perfecta, siguiendo las normas clásicas. En el barroco se trata sencillamente de la decoración de lo material por el uso de figuras sacadas del reino de los arquetipos. En la literatura es igual. El libro pastoril, por ejempio, muchas veces presenta los amores de la corte, generalmente en forma del eterno triángulo amoroso, pero con un cambio de nombres y lugares, la conversión de la gente en pastores. La escritura es una manera de elevarlos a un nivel percibido como más universal, donde los hechos tienen sentido, el ambiente de los Campos Eliseos.

El proceso se nota aún más en las Soledades de Góngora, donde hay una trama absolutamente sencilla: cierto náufrago llega a una playa y es llevado a unas bodas por los pastores que lo encuentran. Pero en el proceso de la narración ni lo más íntimo queda sin elaboración; hasta la carne de la mesa deviene macho cabrío con toda una biografía heroica imaginada. En el Quijote es distinto; su barroquismo se nota sobre todo en dos características. Primero, en su búsqueda de la identidad del caballero ideal, don Quijote sale de sus circunstancias ordinarias para rodear lo que se podría llamar la estructura fundamental de su 
ser, como Alonso Quijano, de palabras, obras y circunstancias pertenecientes al mundo caballeresco. Pero la estructura del texto mismo se lo niega: no hay más que un episodio básico, que es el de la salida de un caballero loco y que resulta en un fracaso completo. Pero, como en el caso de las fugas de Bach, se presenta el tema con una extensa serie de variantes en las que se lee el desarrollo del personaje y sus circunstancias, pero sin progreso, sin éxito en lo esencial de la situación.

Tal vez vienen más al caso del barroquismo de la América Latina en el momento actual, algunos poemas de Quevedo: "Erase un hombre a una nariz pegado", con toda una serie de intentos, casi frenéticos, de ilustrar lo grotesco de la nariz monumental. En este caso la estructura básica es la de un hombre con una nariz descomunal. Se empieza por una exageración en forma de inversión: el hombre pegado a la nariz. Pero luego el apéndice es comparado a varias entidades conocidas por su tamaño; algunas vienen al caso y otras pertenecen totalmente al género del esperpento, por lo grotesco. La pirámide de Egipto, por ejemplo, es graciosa porque tiene más o menos la forma de una nariz. Pero la exageración llega a tal punto que la nariz se nos presenta como "las doce tribus de narices", metáfora admisible sólo como arquetipo de lo descomunal. En Quevedo, tanto como en la novela hispanoamericana, se notan un énfasis en lo extremo y una tendencia a jugar con la palabra y la imagen.

Pero ¿por qué reaparece esta clase de barroquismo en la novela hispanoamericana? ¿Por qué estos juegos interminables con el lenguaje, con los narradores y sus múltiples puntos de vista? ¿Puede ser que hayamos llegado a una nueva expresión de la Contrarreforma, una reacción contra una revolución de la conciencia humana? Por lo menos hay aquel sentido del "mundo al revés" que se ha notado en muchas obras literarias, y una revolución que ha dejado al mundo en tales condiciones pone en duda la mera posibilidad de progreso. En efecto, desde principios del siglo se ha notado la tendencia de la novela a adoptar una estructura circular, como en el caso bien conocido de Los de Abajo. El tiempo es cíclico, se ha negado el tiempo lineal, y nos encontramos en una situación en que debemos hacer algo positivo de lo dado. Así hemos llegado a la situación de los escritores de la España de la Contrarreforma, a quienes les fue dado un cuerpo de doctrina que no se les permitía modificar, pero dentro del cual estaban libres para funcionar, elaborancio esa ideología ad infinitum. $\mathrm{Y}$ así nació el barroco. Para nuestros autores hispanoamericanos, sin embargo, no se trata de ninguna ideología dada, sino de un mundo en que es difícil creer en el progreso, en el mejoramiento. La estructura circular de las obras de Carpentier es bien conocida: cada revolución conduce a otra tiranía, que en realidad es la misma. No se trata realmente del apocalipsis, que es circular a su manera, terminando en una nueva creación, sino del cataclismo en el peor de los casos. Es que no se espera ninguna renovación del cosmos por las fuerzas sociopolíticas. Por eso hay que trabajar con las materias dadas para crear un mundo nuevo dentro del caos existente, y la materia más básica de la creación es el lenguaje. 
En efecto, mientras en el siglo diecisiete la tendencia barroca tenía que ver con un intento de conservar una doctrina dada para conservar el mundo deseado, aquí es lo opuesto: ese mundo conocido ya ha desaparecido y lo que queda es un profundo sentido de cataclismo, un cosmos en desintegración.

Por eso, entonces, el intento barroco de crear un nivel de decoración sobre las estructuras básicas. El caso del Bustrófedon de Tres tristes tigres es instructivo. Bustrófedon empieza, como don Quijote, con un nombre tan fácil de olvidar que no se recuerda en el texto, y escoge uno nuevo en un libro, en su caso el diccionario. En un mundo en plena desintegración la identidad personal está también en peligro y el silogismo implícito de este personaje será el siguiente: 1) el mundo es creado por el lenguaje; 2) yo soy una parte de dicho mundo; 3) yo soy creado por el lenguaje. El corolario es: Si logro ser inmortal será a través del lenguaje. Por eso Bustrófedon, quien "quiso ser el lenguaje", escoge una figura retórica como nuevo nombre. Esta figura retórica se refiere a la posibilidad de escribir en dos direcciones, y su autor llama a Bustrófedon "the two-way man" 2. El hecho es que el héroe tradicional descrito por Joseph Campbell se llama "Master of Two Worlds"3, el físico y el metafísico. Bustrófedon teme "pasar al otro lado del espejo" sin poder volver, y espera que, como una forma del lenguaje que se mueve en ambas direcciones, pueda volver a la vida. Se puede decir que sobre la estructura básica de su ser él ha establecido una elaboración que pertenece al mundo de las formas que no cambian.

Pero como héroe él también se encuentra encargado de la tarea de derramar su supuesto poder sobre su pueblo. Assí, por ejemplo, un amigo cuyo nombre no aparece en el texto se convierte en Códac, porque es fotógrafo, y dice de Bustrófedon, "Encubrió mi nombre prosaico, habanero con la poesía universal y gráfica" (p. 221). El nombre en cuestión es un cierto Korda, fotógrafo y amigo de Cabrera Infante. Relacionado al reino inmortal por el lenguaje creador, la persona debe poder sobrevivir. Este es el caso también de Ribot, bongosero sin suerte, cuyo nombre, en manos de Bustrófedon, se convierte en Eribó, nombre del dios supremo del culto religioso afrocubano, quien es supuestamente inmortal. Es decir, el propósito de Bustrófedon es elevarlos al nivel de la inmortalidad al darles nombres universales y por lo tanto inmortales.

En la ideología de Tres tristes tigres lo único perdurable es el lenguaje, y el sentido neobarroco que le da el autor en su juego constante con las palabras, en un intento de probar todas la variaciones posibles, revela una creencia de que del lenguaje surge el único cosmos eterno y que, por lo tanto, una palabra. confusa no es más que otra manifestación de la massa confusa de los alquimistas -la materia prima de la cual surgió el mundo en la primera instancia. O por

\footnotetext{
${ }^{1}$ Guillermo Cabrera Infante, Tres tristes tigres (Barcelona: Scix Barral, 1967) 318. Las siguientes referencias aparecen en el texto.

2 "Cantando las 40", Suplemento de Imagen 42 (1/15 febrero de 1969).

${ }^{3}$ The Hero with a Thousand Faces (Cleveland y Nueva York: World Publishing Co., Inc., 1956) passim.
} 
lo menos ésta es la esperanza de Bustrófedon, y él ha contagiado a sus amigos, menos a Arsenio Cué, cuya esperanza está en los números. Por ejemplo, Códac, aunque fotógrafo, decide que una de las palabras de Bustrófedon vale por mil imágenes (p. 219), y Silvestre, descrito varias veces como "el discípulo", narra el último tercio del libro en el estilo del maestro. Hasta Cué, borracho, se mete en el loco juego de palabras de "Bachata". ¿Y qué ha logrado Bustrófedon al negarse a dejar su identidad donde estaba, construyendo sobre ella una estructura barroca de palabras en su intento de "ser el lenguaje"? En un sentido ha logrado su propósito, porque todo lo que tenemos de él es su existencia lingüística en el libro: en efecto Bustrófedon es su palabra, y así es inmortal, por lo menos si la novela lo es. Y no es raro si recordamos que Miguel de Unamuno declara que don Quijote posee más vida que Cervantes, siendo el uno un hombre de carne y hueso y el otro un compuesto de meras palabras.

$Y$ ésta es la teoria de Cabrera-Infante: que cualquier personaje que entra en el texto, sea de carne y hueso o completamente inventado, es ficticio. El autor nos advierte desde el principio que todo lo que tenemos son voces, y luego nos da una serie de pruebas, una de ellas en el segmento titulado "Los visitantes". En una entrevista el autor ha dicho, "The game played with 'The Visitors' is practically central to the book, which is either gained or lost right here" ${ }^{m_{4}}$. Es que aqui se construye un personaje distinto del presentado en el prólogo, y luego se lo destruye en el acto, solamente para presentarlo al final completamente distinto. Las diferentes presentaciones de William Campbell desde el principio, con su constante transformación proteica, deben servir de advertencia, pero al llegar al momento culminante, hay la tentación de creer que esta vez sí hemos llegado a la verdad del caso Campbell, es decir al tema cuyas variantes se han desarrollado a través de la narrativa. Silvestre saca de su bolsillo un recado del editor de Carteles, quien firma solamente "GCI" (pp. 438-39). Se supone que por fin el autor, bien conocido como "GCI", se ha metido en el texto como portador de la verdad en cuanto a Campbell y a la confusión de "Los visitantes" en general. Pero éste no es el caso, porque ya se le ha advertido al lector que el que aparece en el libro es personaje de ficción, y lo que trae consigo es igualmente ficticio.

Hay que notar primeramente que cualquier autor es libre para inventar detalles verosímiles en cuanto a sus personajes, y el curriculum vitae de Campbell lo es: es profesor de literatura hispánica en una universidad de Baton Rouge, Louisiana; ha escrito varios libros; la ocasión de su visita a Cuba que produjo la materia de su cuento fue un artículo que escribió para Sports Illustrated sobre la "Havana Sports Car Rally". Esto es verosímil pero no verídico. A fin de cuentas, William Campbell es un ser hecho de palabras, tanto como "GCI" y Rine Leal, inventor de la pésima traducción del cuento de

4 "Caín by Himself: Guillermo Cabrera Infante, Man of Three Islands", compilado por William L. Siemens, Review 29 (enero/abril 1981): 10. 
Campbell y las correcciones de su esposa, pero amigo de Cabrera Infante en la vida real.

Uno de los problemas claves del recado es el desdoblamiento de la imagen del autor en él. Silvestre posee características que obviamente corresponden a las del autor: es bajo y algo grueso, tiene problemas con la visión, es escritor, trabaja para Carteles. Pero ¿qué sucede con "GCI", editor de Carteles? Es otro truco del autor para recordar al lector que absolutamente todo es ficción y que no hay que fiarse de una serie de coincidencias. Para nuestros propósitos lo importante es notar que se trata de otro caso barroco: la presentación de un tema, el de un personaje semejante a lo que conocemos del autor, y una variante del mismo, que es otro personaje que corresponde aún más a dicho autor, pero absolutamente capaz de fabricar una mentira, puesto que toda ficción es una mentira creadora.

Las variantes sobre el tema de la realidad de Campbell, como ya se ha dicho, aparecen en lo que dice el MN del Tropicana de él y lo que Campbell dice de sí mismo en "Los visitantes", con los comentarios de su esposa en la misma sección. Esencialmente, el MC inventa una biografía breve para el personaje; Campbell la modifica radicalmente, y la esposa (inventada por Campbell para el cuento) la cambia aún más. Lo que tenemos, pues, es un personaje completamente inventado, pero, al parecer, una persona real fuera de los límites de la narrativa: éste es el tema. Luego el MC, no sabiendo nada más que el nombre del personaje, pero, para darle interés a su serie de presentaciones, da una impresión de dicho personaje muy distinta. Más tarde, el personaje habla por sí mismo y modifica lo dicho, dejando que otro personaje inventado por él modifique lo que Campbell dice. Sólo al final se le da al lector la estructura básica del personaje, y eso sólo desde el punto de vista establecido por Silvestre; es decir, que según la realidad de ficción inventada por Silvestre, William Campbell posee las características descritas por "GCI". En este caso también se percibe una estructura básica lingüística con varios niveles de elaboración, aunque aquí se le da al lector la elaboración antes que lo básico, para quitar lo falso varias veces antes de llegar al final, donde la última trampa lo invita a creer otra mentira. Lo importante es que la estructura entera se deshace si no se la acepta exactamente como lo que es: una fabricación del lenguaje.

La estrella es otro personaje que se elabora de esta manera. Su "estructura básica" es la de una mulata gorda, de mucha carne y hueso abundante, que cantó en La Habana en la época en cuestión. Su fotografía aparece en el sobre de un disco suyo que lleva el título "Freddy". La elaboración empieza cuando Cabrera Infante le cambia el nombre a "Estrella", indicación evidente de su destino. Ella misma lo subraya al denominarse "La Estrella". El hecho que lleva a este personaje al nivel de un fenómeno cósmico es su encuentro con el fotógrafo Códac, narrador de la sección titulada "Ella cantaba boleros". El lector se encuentra inmerso en una visión dominada por la imagen visual, aunque esto cambia por completo después. 
El recurso estructurante fundamental de la visión un tanto borrosa de Códac borracho es el del "mundo al revés", y para este fotógrafo esto significa una imagen fotográfica negativa. Por eso casi resulta un choque ontológico cuando Códac encuentra a La Estrella por primera vez. Silvestre declara que la búsqueda ontológica de Códac se basa en el deseo de que todas la mujeres tengan una sola vagina (p. 318); es decir que tiene la obsesión de unirse sexualmente con todas las mujeres a la vez. La noche del encuentro, él e Irenita están besándose frenéticamente en la oscuridad de un cabaret. Irenita representa un extremo de lo femenino: es diminuta, rubia y artificial, una creación de la luz. Desde este punto de vista, en la oscuridad, Códac súbitamente percibe a La Estrella en la luz de la escena, y su mundo se vuelve al revés. Es un caso de lo que Platón llama la enantiodromia: la conversión de una entidad en su opuesto cuando llega al extremo.

Desde este momento La Estrella se presenta a través de la voz de Códac, y es una voz cada vez más alucinada, porque para el fotógrafo ella es la suma de todas la mujeres, la Madre Tierra. El problema es que, como tal, ella es demasiada mujer para él, y todo termina en una pesadilla para Códac y una muerte icárica, en México, para ella. Sin embargo, en todo eso hay que considerar dos hechos importantes: primero, el hecho de que otra vez se observa una tremenda elaboración lingüística por encima de una estructura básica y, en segundo lugar, que aún dentro de la misma elaboración hay una simplificación progresiva. Lo que ocurre es que mientras se está desarrollando la relación entre el fotógrafo y el fenómeno visual de La Estrella, también se desarrolla otra relación entre Códac y Bustrófedon, en la cual aquél termina diciendo que una de las palabras de éste vale por mil imágenes. Así que empieza como una elaboración visual, y termina en una idea tan sencilla como "La Estrella es su Voz" (p. 115), frase también barroca, a su manera, por hiperbólica. Esta es una novela compuesta enteramente por voces, y es justo que al final el personaje considerado central por el autor se reduzca a su voz.

Una parte del libro que recuerda la estructura musical de una composición barroca es "Seseribó". Se empieza por un cuento sencillo tomado del folklore afrocubano, el del dios Ekué y la muchacha Sikán. Ella lo saca del río, él se muere de vergüenza, y las pieles de los dos se convierten en el doble tambor llamado "Seseribó". El tambor hecho de la piel de Sikán no se toca. A continuación hay un cuento más o menos largo narrado por el bongosero Ribot, conocido como Eribó gracias a Bustrófedon. El cuento tiene que ver, en su mayor parte, con el mismo Eribó, Arsenio Cué y Vivian Smith-Corona.

Lo que aparece, entonces, es lo siguiente: 1) un personaje cuyo apodo es el nombre del máximo dios del culto religioso afrocubano, nombre que forma parte del "seseribó"; 2) otro personaje cuyo nombre es semejante al del dios Ekué y 3) un tercer personaje cuyo nombre puede leerse como "Vivían", si se le añade un simple acento. El cuento es esencialmente el del fracaso social de Eribó, no sólo 
con la rica Vivian, sino irónicamente con la famosa Cuba Venegas, a quien él cree que descubrió cuando ella no era más que Gloria Pérez. "Sic transit Gloria Pérez" es su comentario (p. 104). La escena clave, sin embargo, es aquélla en que Cué lleva a Eribó al hotel donde vive Vivian y lo deja con ella mientras él charla con otras muchachas. Después Vivian es descrita como una máquina de escribir de vitrina: se mira pero no se toca (p. 109). Ella le revela a Eribó que en efecto ella ha tenido relaciones con alguien, pero que él no debe contárselo a nadie. El cuento termina con las palabras de él: "Seré una tumba" (p. 119).

Parece obvio que el autor quiere presentar el segmento como un tema con sus variantes. La pregunta es en qué sentido la narrativa de Eribó sirve de variante del cuento folklórico. Si Vivian juega el papel de Sikán, hay que averiguar cómo caben Cué/Ekué y Eribó/Seseribó dentro del esquema. La clave se encuentra, no en el cuento mismo, sino más tarde, en "Bachata", cuando Cué, ya perdidamente borracho, le cuenta a Silvestre cómo Vivian lo sacó de su existencia hermética y lo indujo a acostarse con ella, estando ambos borrachos (p.433). Es su versión del acontecimiento arquetípico: Sikán sacó a Ekué de su río y Vivian sacó a Cué de su mundo protegido. Es aquí donde Cué tuerce la leyenda para protegerse. Se siente fatalmente atraído por Vivian, pero a la vez le teme. Sólo puede verla empleando al pobre Eribó como una suerte de aislador, otro yo, para él poder seguir "vivo".

Resulta una situación en que, si los participantes siguen vivos, por lo menos el amorío está bien muerto, y es aquí donde el nombre de la muchacha debe leerse como "Vivían". Si la mitad femenina del seseribó no se toca, tampoco se toca la máquina de escribir que es Vivian Smith-Corona. Y si Ekué termina como la otra mitad del tambor seseribó, Eribó se encuentra diciendo, "Seré una tumba" en los dos sentidos. En su esencia, entonces, el segmento del texto bajo el título de "Seseribó" es un cuento primitivo acompañado de una variante narrada por Eribó, pero fabricada por Arsenio Cué para salvarse de lo que se percibe como una mujer devoradora.

Ya hemos hablado del "mundo al revés" percibido por Códac. Hay otro concepto del fenómeno en el texto, que se nota en su misma estructura. Es que el libro se concibe como una serie de temas que se presentan en la primera mitad y se vuelven al revés en la otra mitad, al pasar por un "espejo" colocado en el centro. Algunos ejemplos - sencillos o increíblemente complejos- son los siguientes: 1) El libro empieza con el sonido de la voz del MC del Tropicana y termina en la repetida mención del silencio; 2) la "expulsión del Paraíso" de los amantes, que tiene lugar en el principio, debe terminar con el suicidio de la mujer de una manera muy cubana: la de su inmolación, según me dice el autor, pero esa parte de la narrativa fue eliminada antes de la publicación. Hacia el final de la novela, Cué relata el sueño de cierta amiga suya, de un perro encendido en una playa y sacado del fuego por otro perro; Cabrera Infante me dice que esto sólo se entiende a base de lo quitado del otro cuento, de manera que 
en la primera parte del manuscrito original una mujer se mete en el fuego, y en la última un perro es sacado de él; 3) un personaje que se llama Beba, pero llamada Babel por Cué, aparece en la primera parte en el papel de la Torre de Babel; habiendo ascendido socialmente y terminado en una confusión de las lenguas aparece en "Bachata" como otra Babel Bíblica, la Babilonia del Apocalipsis, es decir, como la gran prostituta; 4) como ya lo hemos mencionado, William Campbell inventa una historia en "Los visitantes" que se desata en el final en el recado de "GCI" a Silvestre, y 5) una historia contada por Silvestre en "Los debutantes" se cuenta al revés en ciertos detalles en el final, y la historia de Cué de su supuesta muerte en "Los debutantes" tiene su conclusión en su resurrección, contada por él mismo, también en "Bachata".

Pero ¿cuál es el espejo que le da al lector esta imagen al revés del mundo dado? El segmento que ocupa el centro del texto, entre estas situaciones opuestas, se llama "Rompecabeza", y es propiedad de Bustrófedon, quien quiso ser el lenguaje. Por supuesto, si el verbo lo creó todo, es el verbo el que lo pone al revés. Y la clave es el gran amor y respeto que Cabrera Infante siente por Lewis Carroll. Bustrófedon, en efecto, es una extensión de Humpty Dumpty, el que era capaz de manejar el lenguaje a su voluntad: "When $I$ use a word ... it means exactly what I chose it to mean" Este es el propósito de Bustrófedon en sus interminables juegos de palabras. Y mientras que Humpty Dumpty muere estrellado en el pavimento, su avatar Bustrófedon muere de otras causas y abren su cabeza en la autopsia; de alli el título "Rompecabeza".

Tampoco hay que olvidarse del significado del nombre escogido para si por este héroe del lenguaje: Bustrófedon, recurso retórico en que el lenguaje va en una dirección, en una línea, para ir al revés en la próxima. Si Bustrófedon entra en el espejo de Lewis Carrol, siempre puede salir de nuevo. Para él, el espejo significa la muerte, y esto se presenta como un principio sumamente importante para él: ser el lenguaje, y especificamente el lenguaje que se mueve en las dos direcciones, significa la posibilidad - tal vez la única posibilidad- de la inmortalidad. Y el libro mismo, siendo lenguaje y como tal emparentado con Bustrófedon, también entra en el espejo y se pone al revés para completarse.

El juego principal de Bustrófedon en su segmento del texto es su parodia de varios autores cubanos a través de lo que él se imagina que ellos harian con la historia de la muerte de León Trotsky. Trotsky, en realidad, sirve de otroyo para Bustrófedon, siendo los dos herejes que mueren por la causa (un defecto del cerebro causa el juego lingüístico de Bustrófedon tanto como su muerte) y sufren el rompimiento del cráneo, Trotsky por el hacha y Bustrófedon por la autopsia. Cada versión de los hechos históricos imaginada por Bustrófedon constituye un nivel barroco de la elaboración. Hasta hay una versión de José Martí, mártir él mismo, supuestamente escrita unas décadas antes de los hechos. El efecto total es el desvanecimiento del hecho histórico bajo el peso de la imaginación y la

${ }^{5}$ Lewis Carroll, The Annotated Alice, introducción y notas por Martin Gardner (Nueva York: Bramhall House, 1960) 269. 
estilización. Este es un siglo en que hasta los científicos insisten en que la realidad depende de la percepción del observador; aquí el lector se da cuenta de que lo único que posee de la muerte de Trotsky son unos reportajes periodísticos de México o, alternativamente, estos resultados de la imaginación novelística creados por un personaje creado. Y asi es cuando se trata del estilo barroco, donde el decorado a veces termina siendo de más importancia que la estructura básica.

Pero para Bustrófedon esto no es lo esencial. Es que, como Cervantes, Quevedo y Góngora, él percibe que el mundo material que conoce está en proceso de desintegración, y que su única defensa es el lenguaje que, según se dice, fue la base de la creación original. Si el mundo va a moverse al revés, será bajo la influencia, no sólo de un lenguaje desintegrado, sino de un lenguaje que explora todas las posibilidades. Es por eso por lo que Bustrófedon y sus discípulos se sienten tan entusiasmados al encontrar, por un proceso aleatorio, un nuevo palíndromo significativo o una nueva palabra portmanteau. Para Cabrera Infante, como para Lewis Carroll, se trata de la búsqueda de una realidad superior a la actual. Para Bustrófedon, específicamente, hay deleite en el hecho de que "alergia" puede ser "alegría" con un leve cambio, o que "Adán" es "nada" al revés: si siempre existe la posibilidad de una metamorfosis lingüística, siempre hay la posibilidad de una nueva creación en el mundo material que se deriva del lenguaje. Para el barroco, si no se puede cambiar lo dado, por lo menos se puede ser creador por sobre lo fundamental. El neobarroco cubano concebido por Cabrera Infante es un poco distinto. Puede ser que desaparezca para siempre, y la elaboración representa una búsqueda de todas las posibilidades de una nueva creación a base del lenguaje. 
